\title{
A New Technological Advancement of the Drug-Induced Sleep Endoscopy (DISE) Procedure: The "All in One Glance" Strategy
}

\author{
Michele Arigliani ${ }^{1, *(\mathbb{D}}$, Domenico M. Toraldo ${ }^{2} \mathbb{( D}$, Filippo Montevecchi ${ }^{3}$, Luana Conte ${ }^{4,5} \mathbb{D}_{\text {, }}$ \\ Lorenzo Galasso $^{6}{ }^{(0}$, Filippo De Rosa ${ }^{7}$, Caterina Lattante ${ }^{7}$, Enrico Ciavolino ${ }^{8}{ }^{\circ}$, \\ Caterina Arigliani ${ }^{9}$ (D), Antonio Palumbo ${ }^{1}$, Michele De Benedetto ${ }^{1}$ and Claudio Vicini ${ }^{10,11}$ \\ 1 ENT Unit, “V.Fazzi” Hospital, 73100 ASL Lecce, Italy; antopal56@virgilio.it (A.P.); \\ micheledebenedetto@hotmail.it (M.D.B.) \\ 2 Department of Rehabilitation, Cardiorespiratory Rehabilitation Unit, “V.Fazzi” Hospital, \\ 73100 ASL Lecce, Italy; toraldodomenico@gmail.com \\ 3 ENT \& Oral Surgery Unit, Private Hospitals, 47121 Forli, Italy; filippomontevecchi72@gmail.com \\ 4 Laboratory of Interdisciplinary Research Applied to Medicine (DReAM), University of Salento and \\ ASL (Local Health Authority) at the "V Fazzi" Hospital, 73100 Lecce, Italy; luana.conte@unisalento.it \\ 5 Laboratory of Advanced Data Analysis for Medicine (ADAM), Department of Mathematics and Physics "E. \\ De Giorgi", University of Salento, 73100 Lecce, Italy \\ 6 Independent Scholar, Pisanelli no 25, 73020 Castrì di Lecce (LE), Italy; l.galasso78@gmail.com \\ 7 “V.Fazzi" Hospital, Anesthesia and Intensive Care Department, 73100 ASL Lecce, Italy; \\ filippo.derosa@alice.it (F.D.R.); caterinalattante@alice.it (C.L.) \\ 8 Department of History, Society and Human Studies, University of Salento, 73100 Lecce, Italy; \\ enrico.ciavolino@unisalento.it \\ 9 General Medicine, Univerzita Pavla Jozefa Safarika, 04001 Kosiciach, Slovakia; cate.arigliani10@gmail.com \\ 10 Otolaryngology Head and Neck Surgery, University Hospital of Ferrara, 44124 Cona FE, Italy; \\ claudio@claudiovicini.com \\ 11 Head and Neck Department, ENT \& Oral surgery Unit, G.B. Morgagni-L. Pierantoni, Hospital of Forlì, \\ 47121 Forlì, Italy \\ * Correspondence: michele.mariano.arigliani@gmail.com; Tel.: +39-347-3672487
}

Received: 3 May 2020; Accepted: 11 June 2020; Published: 15 June 2020

check for updates

\begin{abstract}
To illustrate a new technological advance in the standard drug-induced sleep endoscopy (DISE) model, a new machine was used, the Experimental 5 Video Stream System (5VsEs), which is capable of simultaneously visualizing all the decisional parameters on a single monitor, and recording and storing them in a single uneditable video. The DISE procedure was performed on 48 obstructive sleep apnea (OSA) or snoring patients. The parameters simultaneously recorded on a single monitor are (1) the pharmacokinetics and pharmacodynamics of propofol (through the target controlled infusion (TCI) pump monitor), (2) the endoscopic upper airway view, (3) the polygraphic pattern, and (4) the level of sedation (through the bispectral index (BIS) value). In parallel to the BIS recording, the middle latency auditory evoked potential (MLAEP) was also recorded and provided. Recorded videos from the $5 \mathrm{VsEs}$ machine were re-evaluated six months later by the same clinician and a second clinician to evaluate the concordance of the therapeutic indications between the two. After the six-month period, the same operator confirmed all their clinical decisions for 45 out of 48 videos. Three videos were no longer evaluable for technical reasons, so were excluded from further analysis. The comparison between the two operators showed a complete adherence in $98 \%$ of cases. The 5VsEs machine provides a multiparametric evaluation setting, defined as an "all in one glance" strategy, which allows a faster and more effective interpretation of all the simultaneous parameters during the DISE procedure, improving the diagnostic accuracy, and providing a more accurate post-analysis, as well as legal and research advantages.
\end{abstract}


Keywords: obstructive sleep apnea (OSA); drug-induced sleep endoscopy (DISE); propofol; Experimental 5 Video Stream System (5VsEs); bispectral index (BIS)

\section{Introduction}

Obstructive sleep apnea (OSA) syndrome is a condition characterized by the presence of the complete or partial collapse of the upper airway during sleep (apnea and hypopnea, respectively). The consequences are sleep fragmentation associated with rapid intermittent hypoxia (IH) episodes with activation of the sympathetic nervous system and oxidative stress. In addition to the frequent presence of daytime sleepiness [1-4], OSA causes a wide spectrum of cardiovascular, metabolic, and neurocognitive comorbidities, more frequently associated with obesity [5]. In the last few years, studies on OSA have increased considerably, but in clinical practice, the disease is still highly underdiagnosed [6].

In OSA patients who need a better definition of the pathology, in surgical failures, or when patients do not accept continuous positive airway pressure (CPAP) therapy, an analytical procedure known as drug-induced sleep endoscopy (DISE) is used to better design the most suitable alternative treatment. This procedure allows the observation of the characteristics of the different levels of the upper airway, where soft tissue vibrations and/or an obstruction caused by collapse site(s) may be observed. It also allows the better definition of the functional alterations that cause poor adherence during CPAP treatment [7-12]. Notably, in this study, we performed DISE using propofol (propofol-DISE), since it allows for quickly obtaining an optimal level of sedation followed by a rapid post-sedation recovery [13-17]. This drug requires anesthesiologist management, and the use of a target-controlled infusion (TCI) pump is highly recommended [13]. During propofol-DISE, several parameters are evaluated simultaneously: endoscopic pattern; the pharmacodynamic and pharmacokinetic parameters through a TCI pump, which allows an optimal drug infusion modality and the continuous evaluation of drug concentration levels in the blood and brain [15,18-22]; polygraph recording synchronized with endoscopic images [23,24]; as well as the bispectral index (BIS) [25-27], i.e., the level of sedation achieved.

In the literature, several studies have tried to improve the DISE approach currently in use [9], whose major limitation is the subjectivity of the diagnostic-therapeutic decision, which may be associated with the lack of the recording of some parameters. At the moment, the parameters considered during the procedure are represented on several monitors and, with the exception of video endoscopy and polygraphic recording, the current technology does not provide for the recording and storage of the other parameters. In particular, the failure to record and store the pharmacokinetic and pharmacodynamic profiles, as well as the BIS values, that determine the endoscopic video pattern, does not allow an objective re-evaluation of the diagnosis, thus excluding the possibility of post-analysis [23,24,27-29].

The aim of this study was to propose a technological advance over the standard propofol-DISE model using a new machine called the 5 Video Stream Experimental System (5VsEs), which allows the simultaneous display of all the decisional parameters synchronized on a single monitor. The single video is recorded so that the video file cannot be modified or edited and is therefore suitable for use in research.

\section{Materials and Methods}

The DISE procedure was performed in accordance with the European Position Paper [14]. The following medical devices are part of the 5VsEs prototype: (1) a flexible endoscope (rhinolaryngoscope, 11101 series, Karl Storz ${ }^{\circledR}$ CDD, Tuttlingen, Germany); (2) a compatible camera (image 1222010 20, Karl Storz ${ }^{\circledR}$ Tuttlingen, Germany); (3) an American Academy of Sleep Medicine (AASM)-compliant home sleep apnea testing device (Embletta Gold Portable Testing Device ${ }^{\circledR}$, 
RemLogicE ${ }^{\circledR}$ Software 2015, Embla System Inc, Broomfield, US) and its nasal canula and/or thermistors; (4) an oximeter (Nonin XPOD ${ }^{\circledR}$, Plymouth, UK) with finger probe; (5) a BIS system (Covidien Ireland Limited ${ }^{\circledR}$, Dublin, Irland); and (6) a TCI pump (Alaris PK ${ }^{\circledR}$ by Carefusion PK, Basingstoke, UK), plus a middle latency auditory evoked potential (MLAEP) system (A-line ${ }^{\circledR}$ sw version 1.5 , owned by Danmeter A/S Denmark, Odense, Danmark). Detailed description of the 5VsEs is shown in Figure 1.
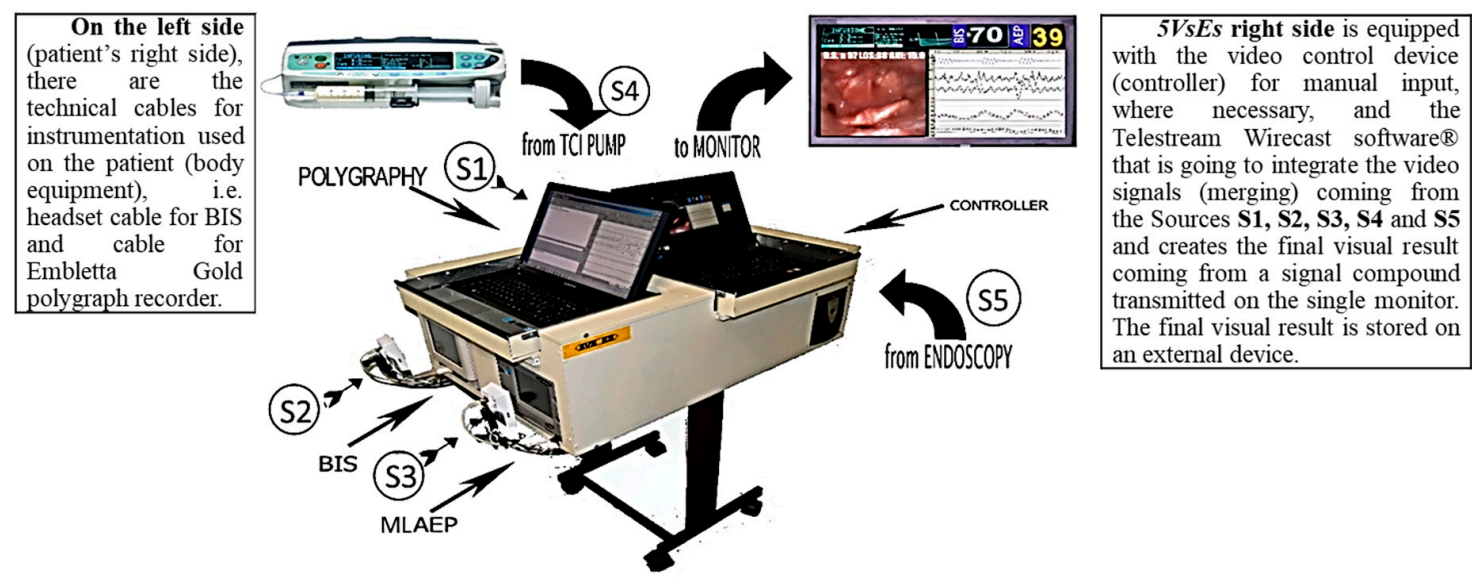

Operator's side. The $5 V_{s} E s$ is equipped with a device for online polygraphy monitoring, i.e. Embletta Gold (S1). The BIS and MLAEP instruments are positioned on the same side on which two HD cameras $(\mathbf{S 2}, \mathbf{S 3})$ are applied. The signal coming from S1 is sent to the VideoGrabber HD with $1080 \mathrm{p}$ resolution. This resolution level allows an optimal reading of the numerical values of the graph generated by the polygraph. The 720p HD video signals from S2 and S3 are transmitted over USB 3.0. The video signal from the Wi-Fi HD camera, related to the TCI pump (S4), is transmitted through a gigabit Wi-Fi switch/router. An additional Video-Grabber HDMI, which transmits the endoscopy video signal, is housed at the back. This video signal, coming from the endoscopy video processor (S5), is acquired through HDMI port with 1080p Full-HD quality. Thanks to this better resolution, it is possible to over-dimension the endoscopic video in order to better evaluate the endoscopic pattern. This is an improvement of the already existing technology which allows to match the online polygraphy monitoring screen with endoscopic screen.

Figure 1. Detailed description of the Experimental 5 Video Stream System (5VsEs).

Patients provided their informed consent prior to participating in the study and international ethical standards were respected.

Age, sex, body mass index (BMI; mean 28, SD 3.6), Epworth Sleepiness Scale (ESS) (mean 12 , SD 2.6), presence of comorbidities (38 patients (79\%) with comorbidities and $10(21 \%)$ without comorbidities), previous treatment $(43(90 \%)$ with no previous treatments and $5(10 \%)$ with confirmed previous treatments), overnight polygraphic values of the apnea hypopnea index (AHI; mean $37 \mathrm{~h} / \mathrm{sleep}$ $(\mathrm{h} / \mathrm{s})$, SD 17.1), oxygen desaturation index (ODI; mean 42 (h/s), SD 17.5), and lowest $\mathrm{SatO}_{2} \%$ (LOS; mean 77\%, SD 11.1), defined according to Toraldo et al. [30] and AASM [8], are shown in Table 1. The sample was strictly random, so the number of women was random too.

Figure 2A shows the current DISE setting. Figure 2B shows the setting of DISE-polygraphy [24] in the first attempt to create a custom version. Figure 2C shows our propofol-DISE procedure set up prior to the use of 5VsEs, in which the operator controls five different data sources from five different devices. Figure 2D shows the operating room and the latest version of $5 \mathrm{VsEs}$.

Figure 3 shows the final output of the 5VsEs represented on a single screen; all decisional parameters with optimized synchronization are displayed on a single high-definition (HD) monitor that integrates (i) the pharmacokinetics and pharmacodynamics of propofol (through the TCI pump monitor), (ii) the endoscopic upper airway view, (iii) the polygraphic pattern, and (iv) the level of sedation (through the BIS value). In parallel to the recording of the BIS, the middle latency auditory evoked potential (MLAEP) was also recorded and provided. The MLAEP system is already used in anesthesiology for the measurement of coma depth [31]; it was included for the first time in the DISE procedure. MLAEP was tested for a comparison with the BIS to evaluate which of the two is faster in determining the level of sedation. The results of this comparison are currently being validated. 
Table 1. Patient characteristics.

\begin{tabular}{|c|c|c|c|c|c|c|c|c|c|c|}
\hline ID Number & $\mathbf{M} / \mathbf{F}$ & BMI & ESS & Comorbidities & $\begin{array}{l}\text { Previous } \\
\text { Treatment }\end{array}$ & $\begin{array}{c}\text { Age } \\
\text { (years) }\end{array}$ & $\begin{array}{l}\text { Drug-induced } \\
\text { Sleep Endoscopy } \\
\text { (DISE) Date }\end{array}$ & AHI (h/s) & ODI (h/s) & LOS (\%) \\
\hline 1 & $\mathrm{M}$ & 28 & 15 & Y & $\mathrm{N}$ & 48 & February 2017 & 26 & 25 & 80 \\
\hline 2 & $\mathrm{M}$ & 30 & 14 & $\mathrm{Y}$ & $\mathrm{N}$ & 43 & February 2017 & 18 & 31 & 81 \\
\hline 3 & $\mathrm{M}$ & 31 & 18 & $Y$ & $\mathrm{~N}$ & 52 & February 2017 & 56 & 50 & 68 \\
\hline 4 & M & 32 & 13 & $\mathrm{Y}$ & $\mathrm{N}$ & 52 & February 2017 & 65 & 77 & 62 \\
\hline 5 & $\mathrm{M}$ & 33 & 12 & $Y$ & $\mathrm{Y}$ & 45 & April 2017 & 12 & 22 & 94 \\
\hline 6 & $\mathrm{M}$ & 34 & 9 & $\mathrm{~N}$ & $\mathrm{~N}$ & 64 & April 2017 & 26 & 30 & 80 \\
\hline 7 & M & 24 & 10 & $\mathrm{~N}$ & $\mathrm{~N}$ & 58 & April 2017 & 27 & 32 & 88 \\
\hline 8 & $\mathrm{M}$ & 29 & 16 & $Y$ & $\mathrm{~N}$ & 53 & April 2017 & 43 & 46 & 64 \\
\hline 9 & $\mathrm{~F}$ & 34 & 15 & $Y$ & $\mathrm{~N}$ & 58 & April 2017 & 53 & 57 & 57 \\
\hline 10 & $\mathrm{M}$ & 31 & 14 & $Y$ & $\mathrm{~N}$ & 56 & April 2017 & 57 & 49 & 84 \\
\hline 11 & $\mathrm{M}$ & 28 & 12 & $Y$ & $\mathrm{~N}$ & 75 & May 2017 & 43 & 49 & 73 \\
\hline 12 & M & 23 & 11 & $\mathrm{Y}$ & $\mathrm{N}$ & 71 & May 2017 & 43 & 47 & 78 \\
\hline 13 & M & 34 & 10 & $Y$ & $\mathrm{~N}$ & 54 & May 2017 & 56 & 73 & 55 \\
\hline 14 & $\mathrm{M}$ & 27 & 15 & $\mathrm{~N}$ & $\mathrm{~N}$ & 41 & May 2017 & 22 & 18 & 82 \\
\hline 15 & M & 28 & 10 & $\mathrm{Y}$ & $\mathrm{N}$ & 47 & June 2017 & 71 & 82 & 78 \\
\hline 16 & $\mathrm{~F}$ & 28 & 13 & $Y$ & Y & 55 & June 2017 & 32 & 36 & 64 \\
\hline 17 & $\mathrm{~F}$ & 19 & 10 & $\mathrm{~N}$ & $\mathrm{~N}$ & 41 & June 2017 & 12 & 22 & 94 \\
\hline 18 & $\mathrm{M}$ & 25 & 13 & $Y$ & $\mathrm{~N}$ & 28 & July 2017 & 27 & 29 & 92 \\
\hline 19 & $\mathrm{M}$ & 27 & 14 & $\mathrm{Y}$ & $\mathrm{N}$ & 45 & July 2017 & 24 & 28 & 89 \\
\hline 20 & $\mathrm{M}$ & 35 & 18 & $Y$ & $\mathrm{~N}$ & 41 & July 2017 & 74 & 79 & 59 \\
\hline 21 & $M$ & 25 & 13 & $\mathrm{Y}$ & $\mathrm{N}$ & 28 & September 2017 & 27 & 29 & 92 \\
\hline 22 & $\mathrm{M}$ & 31 & 11 & $Y$ & $\mathrm{~N}$ & 46 & September 2017 & 58 & 55 & 70 \\
\hline 23 & $\mathrm{M}$ & 25 & 13 & $Y$ & $\mathrm{~N}$ & 48 & September 2017 & 26 & 33 & 82 \\
\hline 24 & $\mathrm{M}$ & 25 & 10 & $\mathrm{~N}$ & $\mathrm{~N}$ & 19 & September 2017 & 27 & 38 & 80 \\
\hline 25 & $\mathrm{M}$ & 31 & 11 & $\mathrm{Y}$ & $\mathrm{N}$ & 41 & November 2017 & 30 & 35 & 84 \\
\hline 26 & $\mathrm{M}$ & 27 & 12 & $Y$ & $\mathrm{~N}$ & 58 & November 2017 & 25 & 35 & 83 \\
\hline 27 & $\mathrm{M}$ & 28 & 12 & Y & $\mathrm{N}$ & 40 & November 2017 & 43 & 48 & 72 \\
\hline 28 & $\mathrm{M}$ & 26 & 11 & $\mathrm{~N}$ & $\mathrm{~N}$ & 60 & November 2017 & 22 & 18 & 88 \\
\hline 29 & $\mathrm{M}$ & 27 & 12 & $\mathrm{~N}$ & $\mathrm{~N}$ & 38 & November 2017 & 28 & 27 & 78 \\
\hline 30 & M & 33 & 14 & $\mathrm{Y}$ & $\mathrm{N}$ & 53 & January 2018 & 36 & 36 & 72 \\
\hline 31 & $\mathrm{M}$ & 32 & 10 & $\mathrm{Y}$ & $\mathrm{N}$ & 51 & January 2018 & 50 & 51 & 77 \\
\hline 32 & M & 26 & 12 & $Y$ & $\mathrm{~N}$ & 56 & February 2018 & 25 & 37 & 81 \\
\hline 33 & $\mathrm{M}$ & 23 & 14 & $\mathrm{Y}$ & $\mathrm{N}$ & 55 & February 2018 & 23 & 30 & 89 \\
\hline 34 & $\mathrm{M}$ & 27 & 12 & $Y$ & $\mathrm{~N}$ & 54 & February 2018 & 52 & 55 & 69 \\
\hline 35 & $\mathrm{M}$ & 34 & 11 & $Y$ & $\mathrm{~N}$ & 68 & March 2018 & 47 & 54 & 63 \\
\hline 36 & $\mathrm{M}$ & 25 & 13 & $Y$ & $\mathrm{~N}$ & 29 & May 2018 & 27 & 32 & 82 \\
\hline 37 & $\mathrm{M}$ & 23 & 9 & $\mathrm{Y}$ & $\mathrm{N}$ & 35 & May 2018 & 26 & 26 & 84 \\
\hline 38 & M & 29 & 11 & $\mathrm{Y}$ & $\mathrm{N}$ & 18 & May 2018 & 58 & 56 & 53 \\
\hline 39 & $\mathrm{M}$ & 33 & 6 & $\mathrm{~N}$ & $\mathrm{~N}$ & 57 & June 2018 & 27 & 33 & 78 \\
\hline 40 & $\mathrm{M}$ & 28 & 9 & $\mathrm{~N}$ & $\mathrm{~N}$ & 62 & June 2018 & 27 & 31 & 83 \\
\hline 41 & $\mathrm{M}$ & 28 & 14 & $\mathrm{Y}$ & $\mathrm{Y}$ & 60 & June 2018 & 22 & 29 & 88 \\
\hline 42 & $\mathrm{~F}$ & 31 & 13 & $Y$ & $Y$ & 56 & July 2018 & 78 & 75 & 59 \\
\hline 43 & $\mathrm{~F}$ & 29 & 19 & $Y$ & $\mathrm{~N}$ & 28 & October 2018 & 57 & 61 & 62 \\
\hline 44 & $\mathrm{M}$ & 23 & 10 & $\mathrm{Y}$ & $\mathrm{N}$ & 57 & October 2018 & 20 & 27 & 88 \\
\hline 45 & $\mathrm{M}$ & 25 & 10 & $\mathrm{Y}$ & $\mathrm{N}$ & 46 & October 2018 & 35 & 72 & 70 \\
\hline 46 & $\mathrm{M}$ & 27 & 12 & $\mathrm{Y}$ & $\mathrm{N}$ & 55 & October 2018 & 25 & 32 & 87 \\
\hline 47 & $\mathrm{M}$ & 30 & 12 & $\mathrm{~N}$ & $\mathrm{~N}$ & 55 & November 2018 & 55 & 57 & 79 \\
\hline 48 & $\mathrm{M}$ & 27 & 6 & $\mathrm{Y}$ & $\mathrm{Y}$ & 36 & November 2018 & 15 & 18 & 90 \\
\hline
\end{tabular}

ID: identification number; M/F: male/female; BMI: body mass index; ESS: Epworth Sleepiness Scale; AHI (h/s): apnea hypopnea index; ODI (h/s): oxygen desaturation index; and LOS (\%): lowest $\mathrm{SatO}_{2} \%$. 
A)

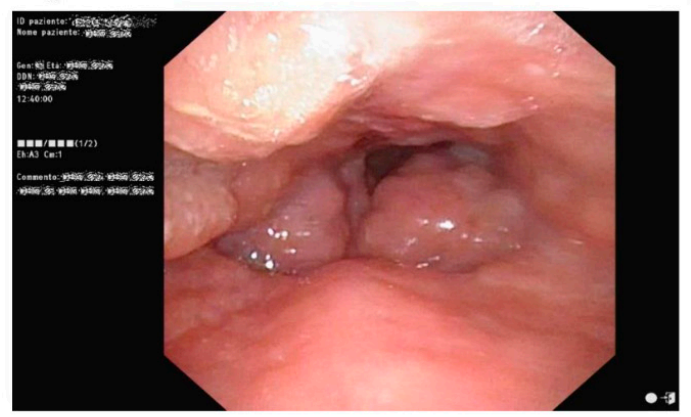

C)

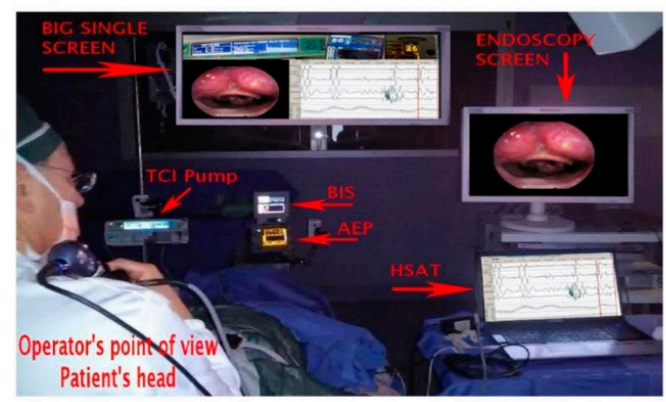

B)

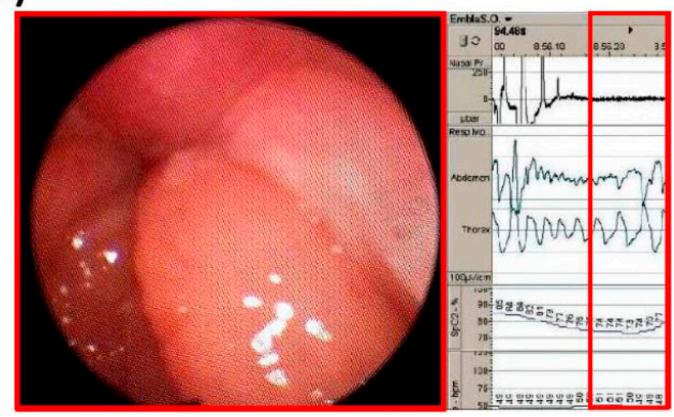

D)

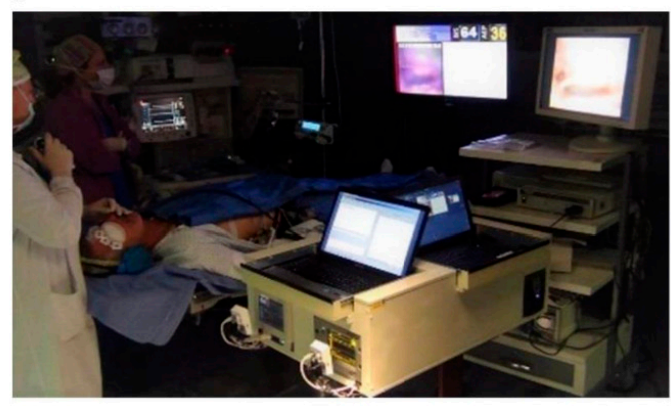

Figure 2. (A) Current drug-induced sleep endoscopy (DISE) setting; (B) customized DISE-polygraphy; (C) propofol-DISE. Prior to the use of the $5 \mathrm{VsEs}$, the operator managed five different data sources from five different devices. (D) The operating room and the $5 \mathrm{VsEs}$.
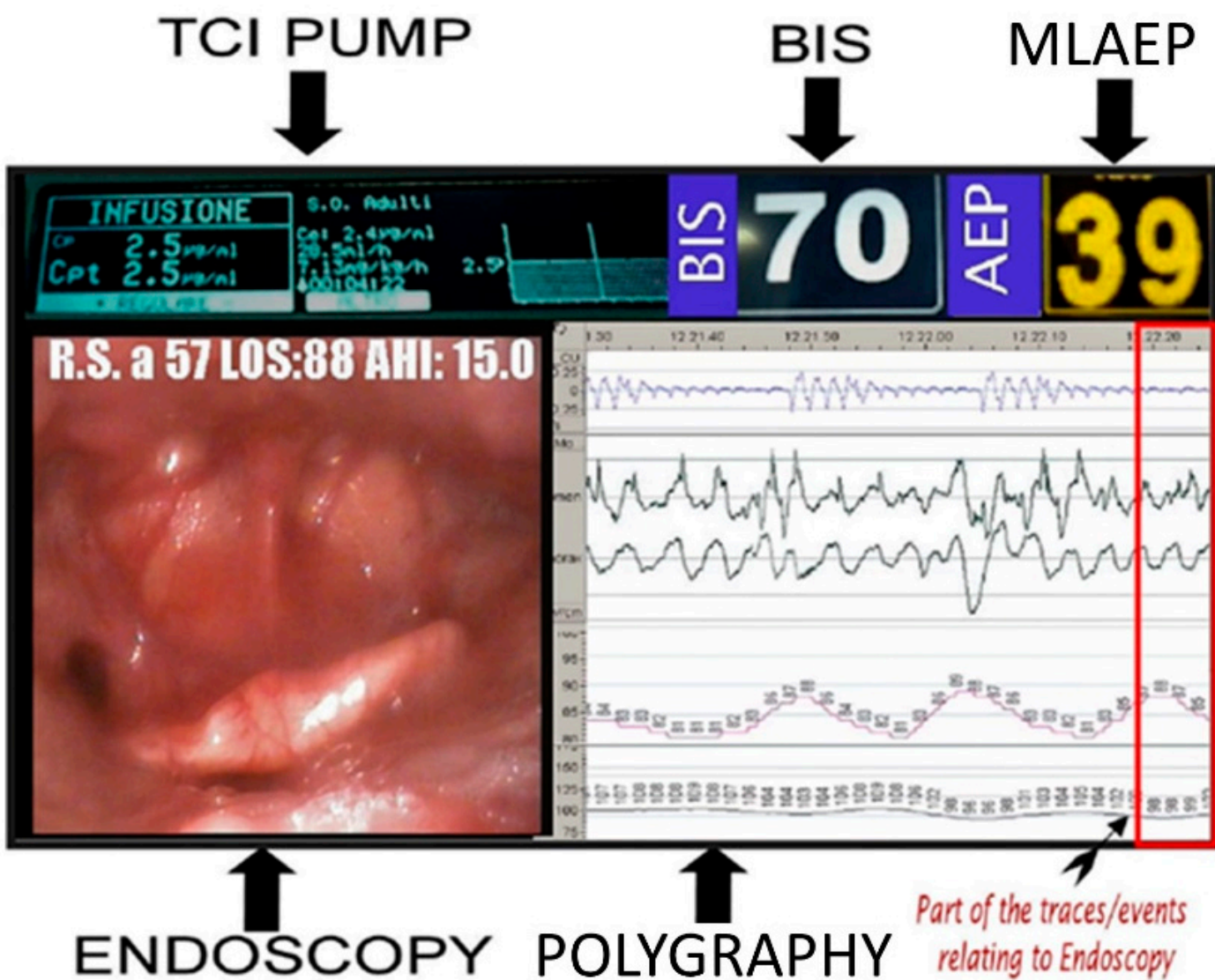

Figure 3. The 5VsEs single screen ("all in one glance" strategy). 
The study was designed so that all procedures were performed by the same operator, who reported their clinical evaluations based on multiparametric observations on a $5 \mathrm{VsEs}$ single screen in the operation theater. The videos were re-evaluated 6 months later by the same operator (intra-operator and delayed evaluation for post-analysis) and by an external clinician (inter-operator evaluation) to evaluate the concordance of the therapeutic indications between the two. The second external operator also had access to the patient's clinical anamnestic data. The second operator was blinded from the first operator's impression so that the result was objective and impartial. The machine was validated by comparing the endoscopic video recording of standard DISE in parallel with 5VsEs. Figure 3 shows the final output of the 5 VsEs.

\section{Ethics Approval}

Research approval was obtained through the Ethics Committee of the Local Health Authority (ASL LE) at the Vito Fazzi Hospital (verbal no. 39, 26 November, 2019) and informed written consent was obtained from all research participants. Informed consent was obtained from all individual participants included in the study.

\section{Results}

A total of 48 OSA patients (43 men (90\%) and five women (10\%), mean age 49 years old, SD 12.5, range 18-75 years) were randomly enrolled in the study from February 2017 to November 2018 at the ENT Department at Vito Fazzi Hospital, ASL Lecce (Italy) (Table 1). Patients were recruited according to the following criteria: patients affected by snoring and/or OSA with surgery or mandibular advancement device (MAD) indication; patients affected by OSA with surgical failures and not compliant with CPAP treatment. Patients with anesthesia risk (ASA) $\leq 3$, patients with a BMI $\leq 35$, patients under 18 years old, pregnant women, and patients with contraindications to propofol infusion were excluded from the study.

After the six-month period (intra-operator delayed evaluation for post-analysis), the same operator confirmed all their clinical decisions for 45 out of 48 videos. Three videos (nos. 8, 10, and 22) were no longer evaluable due to recording failure, so were excluded from further analysis. The therapeutic decisions between the two different operators completely agreed in $91 \%$ of cases (41 cases out of 45 ), which is $98 \%$ considering that in cases 2,16 , and 44 , the difference was only temporal, since the second operator, in contrast to the first, suggested a monitoring period before confirming the treatment or vice versa. In case no. 39, a low impact difference was found between both decisions. The last video out of 45 (case no. 12) was judged not evaluable by the second operator only, in accordance with normal medical judgments. Comparing the decisions made inside and outside the operating room (live/on monitor decision), data analysis seemed to confirm that both the operators were able to make a final clinical decision based on the recorded data in 44 cases out of a total of $45(98 \%)$. The results are reported in Table 2.

Table 2. Results of DISE interpretations based on 5VsEs in the operating room and after 6 months by the same operator compared to a second external operator.

\begin{tabular}{cccc}
\hline ID Number & Instant Decision & Same Operator (6 Months After) & Second Operator \\
\hline $\mathbf{1}$ & BRP & SAME & SAME \\
\hline $\mathbf{2}$ & BRP & SAME & SAME after monitoring \\
\hline $\mathbf{3}$ & BRP & SAME & SAME \\
\hline $\mathbf{4}$ & BRP & SAME & SAME \\
\hline $\mathbf{5}$ & No treatment & SAME & SAME \\
\hline $\mathbf{6}$ & FEP & SAME & SAME \\
\hline $\mathbf{7}$ & BRP & SAME & SAME \\
\hline $\mathbf{8}$ & BRP & Unjudgeable Video Recording & SAME \\
\hline
\end{tabular}


Table 2. Cont.

\begin{tabular}{|c|c|c|c|}
\hline ID Number & Instant Decision & Same Operator (6 Months After) & Second Operator \\
\hline 9 & PSG Lab & SAME & SAME \\
\hline 10 & BRP & Unjudgeable Video Recording & SAME \\
\hline 11 & BRP & SAME & SAME \\
\hline 12 & BRP + Epiglottoplasty & SAME & Unjudgeable Video Recording \\
\hline 13 & CPAP & SAME & SAME \\
\hline 14 & FEP + MAD & SAME & SAME \\
\hline 15 & MMA & SAME & SAME \\
\hline 16 & $\mathrm{BRP}+\mathrm{MAD}$ & SAME & BRP Monitoring before MAD \\
\hline 17 & MAD & SAME & SAME \\
\hline 18 & BRP & SAME & SAME \\
\hline 19 & $\mathrm{BRP}+\mathrm{MAD}$ & SAME & SAME \\
\hline 20 & BRP & SAME & SAME \\
\hline 21 & $\mathrm{BRP}+\mathrm{MAD}$ & SAME & SAME \\
\hline 22 & $\mathrm{BRP}+\mathrm{TORS}$ & Unjudgeable Video Recording & SAME \\
\hline 23 & BRP + Thyro-Hioido-Pexy & SAME & SAME \\
\hline 24 & BRP & SAME & SAME \\
\hline 25 & FEP & SAME & SAME \\
\hline 26 & FEP & SAME & SAME \\
\hline 27 & BRP + GlossoEpiglottopexy & SAME & SAME \\
\hline 28 & BRP & SAME & SAME \\
\hline 29 & BRP & SAME & SAME \\
\hline 30 & Septoplasty + BRP & SAME & SAME \\
\hline 31 & BRP & SAME & SAME \\
\hline 32 & BRP & SAME & SAME \\
\hline 33 & No treatment & SAME & SAME \\
\hline 34 & BRP & SAME & SAME \\
\hline 35 & BRP and Monitoring & SAME & SAME \\
\hline 36 & BRP and Monitoring & SAME & SAME \\
\hline 37 & Septoplasty + BRP & SAME & SAME \\
\hline 38 & MMA + Epiglottoplasty & SAME & SAME \\
\hline 39 & $\mathrm{BRP}+\mathrm{MAD}$ & SAME & BRP \\
\hline 40 & FEP & SAME & SAME \\
\hline 41 & $\mathrm{BRP}+\mathrm{MAD}$ & SAME & SAME \\
\hline 42 & $\mathrm{BRP}+\mathrm{MAD}$ & SAME & SAME \\
\hline 43 & diet + CPAP & SAME & SAME \\
\hline 44 & Wait \& See for Epiglottoplasty & SAME & Epiglottoplasty and monitoring \\
\hline 45 & BRP & SAME & SAME \\
\hline 46 & BRP & SAME & SAME \\
\hline 47 & BRP and Monitoring & SAME & SAME \\
\hline 48 & MAD & SAME & SAME \\
\hline
\end{tabular}

FEP: Functional expansion pharyngoplasty; PSG-lab: polysomnography in laboratory; BRP: barbed reposition pharyngoplasty; MAD: mandibular advancement device; MMA: maxillo-mandibular advancement; TORS: trans-oral robotic surgery; CPAP: continuous positive airway pressure. 


\section{Discussion}

With the current standard DISE setting, some important details and information may be missed because the operator has to control several monitors simultaneously. The inability to save all parameters, with the exception of the video endoscopy and polygraphy [23,24,27-29], does not allow the subsequent re-evaluation of the entire procedure, excluding the possibility of a post-analysis and a second clinical opinion. The DISE procedure, allowing an endoscopic representation of the pathophysiology of OSA in a pharmacologically induced sleep situation, cannot be considered a simple endoscopy video; rather, it is a fluid concatenation of drug dynamic events linked to pathophysiological events that generate the endoscopic image moment by moment. Consequently, no correct post-analysis is possible when only the endoscopic and polygraphic pattern is stored without storing the drug dynamic context and the relative sedation level. The lack of pharmacokinetic and pharmacodynamics profiles storage in the current DISE makes the procedure highly subjective because the DISE procedure is partially documented. Instead, $5 \mathrm{VsEs}$ easily visualizes and stores the pharmacology of propofol through the TCI pump, which makes the procedure objective because it is documented and therefore verifiable at the time. Since the second operator was blinded from the first operator's impression, the final decision was only based on the recorded data; the agreement/disagreement rate suggested the possibility of making diagnostic and therapeutic decisions based on the video and medical record documentation. In only one case, the agreement between the two operators was influenced by the variability of medical judgements. Under normal conditions, data recorded during the DISE procedure are displayed quickly on several monitors. When the manual transcription of data is required for clinical and study purposes, it may be inaccurate and often unreliable due to errors caused by rapid subsequent changes in values. The 5VsEs technology, conversely, allows complete data recovery through post-analysis.

In the literature [9], several research groups have highlighted the difficulty of standardizing results obtained during the standard DISE procedure, given the associated technical problems. In this paper, we illustrate the 5 VsEs machine, which is a new approach and a technological advancement developed to overcome the issues with the standard procedure. The first target achieved was to display the five different signals for all the parameters, normally dissociated from each other, on a single monitor (video endoscopy, polygraphy, TCI, BIS, and MLAEP). The consequent effect was to construct an "all in one glance" approach enabled by the visualization and synchronization of the decisional parameters of DISE on a single monitor, guaranteeing a better perception that contributes to a more correct definition of the observation window. The optimized synchronization of all the monitors and the reduction and homogenization of the latency response between the different instruments allow the correct interpretation of the decision parameters and do not to interfere with the operator's manual skills. The 5VsEs machine also ensures a certain speed and comfort of use, since the operator only has to place the sensors on the patient to start the procedure. In addition, to improve the quality of the endoscopic image and to better highlight the readability of the numerical values present in the polygraph traces, we also used HD video, which is rarely used in DISE [24]. Another important difference compared to the standard DISE is the possibility of recording the entire procedure, saving the output of the machine (Figure 3) on a removable electronic support, which can be used to re-evaluate the entire procedure at a later time, enabling better diagnostic management and providing information that can be used for educational and research aspects, including the possibility of using DISE in multicentric clinical trials and telemedicine. The software used produces a video file that cannot be modified, which enhances its scientific and medical-legal value. The recording of all the parameters deriving from the single screen also allows the storage of all the numerical data, not just the video; therefore, the intra-procedure numerical values (i.e., during the DISE), for example, of the $\mathrm{SatO}_{2} \%$ present in the video recording, can be easily checked and possibly recovered in the event of loss.

The intra-/inter-examination analysis and agreement between both clinicians is related to the "all in one glance" strategy, which depicts of the 5VsEs parameters on a single screen. The completely documented results of this analysis allow the operator (not present in the room) to see all the decision parameters so far not recorded and archived. The evaluation of the recording (Table 3) by the same 
operator after six months (intra-operator evaluation) provided information about the performance of the $5 \mathrm{VsEs}$ machine in the post-analysis phase in terms of our scientific research objective. The inter-operator evaluation provided information about multicentric study performance, medical-legal documentation, and education and teaching aspects.

Table 3. 5VsEs vs. standard technology performance.

\begin{tabular}{ccc}
\hline 5VsEs vs. Standard Procedure & 5VsEs & Standard \\
\hline Documentation of pharmacokinetics-pharmacodynamics profiles & YES & NO \\
\hline Documentation of the observation window & YES & NO \\
\hline Documentation useful for multicentric studies & YES & NO \\
\hline Recovery of lost data during data collection, useful for research purposes & YES & NO \\
\hline Statistical analysis thanks to data collection confidence (uneditable video documentation) & YES & NO \\
\hline Medical-legal documentation more complete & YES & NO \\
\hline Improvement of education and teaching aspects & YES & NO \\
\hline Efficient telemedicine & YES & NO \\
\hline
\end{tabular}

These features could facilitate multicenter studies toward the standardization of the DISE procedure, which, to date, is performed in many different ways. In a systematic review [9], 17 studies were identified that proposed 14 new systems and three modified DISE classification systems to analyze anatomical results based on drug-induced sleep endoscopy. Inter-observer agreement between an experienced observer and an observer in training proposed by Carrasco-Llatas et al. [32] can be easily achieved through the 5VsEs machine. The machine's advantages over the standard DISE are listed in Table 3.

\section{Study Limitations}

Three videos were excluded was due to recording failure. The recordings were sometimes interrupted or discontinued due to the insufficiency of the sensors or when the registration procedure was interrupted for live optimization and live development of the 5VsEs prototype.

\section{Conclusions}

The 5VsEs machine allows a continuous and optimized evaluation and storage of all useful parameters due to the "all in one glance" approach made possible by the integration and synchronization of all DISE parameters on a single monitor. Unlike the standard procedure, 5VsEs permits a non-modifiable full multiparameter recording. The 5VsEs machine was conceived to solve some issues with the method, including methods of the classification of endoscopic patterns, drug infusion techniques, etc. With the $5 \mathrm{VsEs}$ prototype, the operator can continuously evaluate the drug kinetic and pharmacodynamic profiles during the procedure and during re-evaluation in post-analysis and research, which are indispensable for correct evaluation in the post-analysis of the endoscopic pattern along with the BIS data and polygraphic findings. In some situations, the recording was discontinuous, so the next effort will focus on optimizing the prototype. However, this new prototype represents a technological advance in the DISE procedure, allowing for better perception of the observation window. This new diagnostic model needs further studies to validate its reliability in clinical practice on a larger number of patients. The main goal of this work was to present a prototype with interesting and promising potential to improve the management of the DISE procedure and research.

Author Contributions: Conceptualization, M.A. and M.D.B.; methodology, M.A., M.D.B., C.A., and L.C.; software, M.A., L.G., C.A.; validation, M.A., M.D.B., L.G., F.D.R. and C.L.; formal analysis, M.A.; investigation, M.A., M.D.B.; resources, M.A.; data curation, M.A., M.D.B., C.A., L.C. and E.C.; writing-original draft preparation, M.A., M.D.B., L.C.; writing-review and editing, M.A., M.D.B., C.A. and L.C.; visualization, M.A., M.D.B., D.M.T.; supervision, M.A., M.D.B., D.M.T., A.P., F.M., and C.V.; project administration, M.A., M.D.B. All authors have read and agree to the published version of the manuscript. 
Funding: This research received no external funding.

Acknowledgments: The authors would like to acknowledge Adriana Contaldo's contributions in editing this article. The authors also thanks Patrizia Errico, Manuela Greco, Emanuela Tomasi for their technical assistance.

Conflicts of Interest: The authors declare no conflict of interest.

\section{References}

1. Marin, J.M.; Carrizo, S.J.; Vicente, E.; Agusti, A.G. Long-term cardiovascular outcomes in men with obstructive sleep apnoea-hypopnoea with or without treatment with continuous positive airway pressure: An observational study. Lancet 2005, 365, 1046-1053. [CrossRef]

2. Yaggi, H.K.; Concato, J.; Kernan, W.N.; Lichtman, J.H.; Brass, L.M.; Mohsenin, V. Obstructive sleep apnea as a risk factor for stroke and death. N. Engl. J. Med. 2005, 353, 2034-2041. [CrossRef]

3. Kendzerska, T.; Gershon, A.S.; Hawker, G.; Tomlinson, G.; Leung, R.S. Obstructive sleep apnea and incident diabetes. A historical cohort study. Am. J. Respir. Crit. Care Med. 2014, 190, 218-225. [CrossRef]

4. Peppard, P.E.; Szklo-Coxe, M.; Hla, K.M.; Young, T. Longitudinal association of sleep-related breathing disorder and depression. Arch. Intern. Med. 2006, 166, 1709-1715. [CrossRef]

5. Garvey, W.T.; Mechanick, J.I.; Brett, E.M.; Garber, A.J.; Hurley, D.L.; Jastreboff, A.M.; Nadolsky, K.; Pessah-Pollack, R.; Plodkowski, R. Reviewers of the AACE/ACE Obesity Clinical Practice Guidelines American Association of Clinical Endocrinologists and American College of Endocrinology comprehensive clinical practice guidelines for medical care of patients with obesity. Endocr. Pract. 2016, 22 (Suppl. 3), 1-203. [CrossRef]

6. White, D.P. Sleep-related breathing disorder 2. Pathophysiology of obstructive sleep apnoea. Thorax 1995, 50, 797-804. [CrossRef]

7. Georgalas, C.; Garas, G.; Hadjihannas, E.; Oostra, A. Assessment of obstruction level and selection of patients for obstructive sleep apnoea surgery: An evidence-based approach. J. Laryngol. Otol. 2010, 124, 1-9. [CrossRef]

8. Berry, R.B.; Budhiraja, R.; Gottlieb, D.J.; Gozal, D.; Iber, C.; Kapur, V.K.; Marcus, C.L.; Mehra, R.; Parthasarathy, S.; Quan, S.F.; et al. Rules for scoring respiratory events in sleep: Update of the 2007 AASM Manual for the Scoring of Sleep and Associated Events. Deliberations of the Sleep Apnea Definitions Task Force of the American Academy of Sleep Medicine. J. Clin. Sleep Med. 2012, 8, 597-619. [CrossRef]

9. Dijemeni, E.; D’Amone, G.; Gbati, I. Drug-induced sedation endoscopy (DISE) classification systems: A systematic review and meta-analysis. Sleep Breath. 2017, 21, 983-994. [CrossRef]

10. Certal, V.F.; Zaghi, S.; Riaz, M.; Vieira, A.S.; Pinheiro, C.T.; Kushida, C.; Capasso, R.; Camacho, M. Hypoglossal nerve stimulation in the treatment of obstructive sleep apnea: A systematic review and meta-analysis. Laryngoscope 2015, 125, 1254-1264. [CrossRef]

11. Croft, C.B.; Pringle, M. Sleep nasendoscopy: A technique of assessment in snoring and obstructive sleep apnoea. Clin. Otolaryngol. Allied Sci. 1991, 16, 504-509. [CrossRef] [PubMed]

12. Kotecha, B.; De Vito, A. Drug induced sleep endoscopy: Its role in evaluation of the upper airway obstruction and patient selection for surgical and nonsurgical treatment. J. Thorac. Dis. 2018, 10, S40-S47. [CrossRef] [PubMed]

13. De Vito, A.; Carrasco Llatas, M.; Vanni, A.; Bosi, M.; Braghiroli, A.; Campanini, A.; de Vries, N.; Hamans, E.; Hohenhorst, W.; Kotecha, B.T.; et al. European position paper on drug-induced sedation endoscopy (DISE). Sleep Breath. 2014, 18, 453-465. [CrossRef] [PubMed]

14. De Vito, A.; Carrasco Llatas, M.; Ravesloot, M.J.; Kotecha, B.; De Vries, N.; Hamans, E.; Maurer, J.; Bosi, M.; Blumen, M.; Heiser, C.; et al. European position paper on drug-induced sleep endoscopy: 2017 Update. Clin. Otolaryngol. 2018, 43, 1541-1552. [CrossRef]

15. Kotani, Y.; Shimazawa, M.; Yoshimura, S.; Iwama, T.; Hara, H. The experimental and clinical pharmacology of propofol, an anesthetic agent with neuroprotective properties. CNS Neurosci. Ther. 2008, 14, 95-106. [CrossRef] [PubMed]

16. De Vito, A.; Agnoletti, V.; Berrettini, S.; Piraccini, E.; Criscuolo, A.; Corso, R.; Campanini, A.; Gambale, G.; Vicini, C. Drug-induced sleep endoscopy: Conventional versus target controlled infusion techniques-a randomized controlled study. Eur. Arch. Oto-Rhino-Laryngol. 2011, 268, 457-462. [CrossRef] 
17. Hillman, D.R.; Walsh, J.H.; Maddison, K.J.; Platt, P.R.; Kirkness, J.P.; Noffsinger, W.J.; Eastwood, P.R. Evolution of changes in upper airway collapsibility during slow induction of anesthesia with propofol. Anesthesiology 2009, 111, 63-71. [CrossRef]

18. Antkowiak, B.; Kirschfeld, K. Neuronale mechanismen der narkose. Anasthesiol. Intensivmed. Notf. Schmerzther. 2000, 35, 731-743. [CrossRef]

19. Shteamer, J.W.; Dedhia, R.C. Sedative choice in drug-induced sleep endoscopy: A neuropharmacology-based review. Laryngoscope 2017, 127, 273-279. [CrossRef]

20. Rabelo, F.A.W.; Küpper, D.S.; Sander, H.H.; Fernandes, R.M.F.; Valera, F.C.P. Polysomnographic evaluation of propofol-induced sleep in patients with respiratory sleep disorders and controls. Laryngoscope 2013, 123, 2300-2305. [CrossRef]

21. Carrasco Llatas, M.; Agostini Porras, G.; Cuesta González, M.T.; Rodrigo Sanbartolomé, A.; Giner Bayarri, P.; Gómez-Pajares, F.; Dalmau Galofre, J. Drug-induced sleep endoscopy: A two drug comparison and simultaneous polysomnography. Eur. Arch. Otorhinolaryngol. 2014, 271, 181-187. [CrossRef] [PubMed]

22. Eastwood, P.R.; Platt, P.R.; Shepherd, K.; Maddison, K.; Hillman, D.R. Collapsibility of the upper airway at different concentrations of propofol anesthesia. Anesthesiology 2005, 103, 470-477. [CrossRef]

23. Rojewski, T.E.; Schuller, D.E.; Schmidt, H.S.; Clark, R.W.; Potts, R.E. Synchronous video recording of the pharyngeal airway and polysomnograph in patients with obstructive sleep apnea. Laryngoscope 1982, 92, 246-250. [CrossRef] [PubMed]

24. Gobbi, R.; Baiardi, S.; Mondini, S.; Cerritelli, L.; Piccin, O.; Scaramuzzino, G.; Milano, F.; Melotti, M.R.; Mordini, F.; Pirodda, A.; et al. Technique and preliminary analysis of drug-induced sleep endoscopy with online polygraphic cardiorespiratory monitoring in patients with obstructive sleep apnea syndrome. JAMA Otolaryngol. Head Neck Surg. 2017, 143, 459-465. [CrossRef]

25. Babar-Craig, H.; Rajani, N.K.; Bailey, P.; Kotecha, B.T. Validation of sleep nasendoscopy for assessment of snoring with bispectral index monitoring. Eur. Arch. Oto-Rhino-Laryngol. 2012, 269, 1277-1279. [CrossRef]

26. Lo, Y.L.; Ni, Y.L.; Wang, T.Y.; Lin, T.Y.; Li, H.Y.; White, D.P.; Lin, J.R.; Kuo, H.P. Bispectral index in evaluating effects of sedation depth on drug-induced sleep endoscopy. J. Clin. Sleep Med. 2015, 11, 1011-1020. [CrossRef]

27. Johansen, J.W. Update on bispectral index monitoring. Best Pract. Res. Clin. Anaesthesiol. 2006, 20, 81-99. [CrossRef]

28. Veer, V.; Zhang, H.; Beyers, J.; Vanderveken, O.; Kotecha, B. The use of drug-induced sleep endoscopy in England and Belgium. Eur. Arch. Oto-Rhino-Laryngol. 2018, 275, 1335-1342. [CrossRef]

29. Kotecha, B.T.; Hannan, S.A.; Khalil, H.M.B.; Georgalas, C.; Bailey, P. Sleep nasendoscopy: A 10-year retrospective audit study. Eur. Arch. Otorhinolaryngol. 2007, 264, 1361-1367. [CrossRef]

30. Toraldo, D.M.; Nicolardi, G.; De Nuccio, F.; Lorenzo, R.; Ambrosino, N. Pattern of variables describing desaturator COPD patients, as revealed by cluster analysis. Chest 2005, 128, 3828-3837. [CrossRef]

31. Kurita, T.; Doi, M.; Katoh, T.; Sano, H.; Sato, S.; Mantzaridis, H.; Kenny, G.N. Auditory evoked potential index predicts the depth of sedation and movement in response to skin incision during sevoflurane anesthesia. Anesthesiology 2001, 95, 364-370. [CrossRef]

32. Carrasco-Llatas, M.; Zerpa-Zerpa, V.; Dalmau-Galofre, J. Reliability of drug-induced sedation endoscopy: Interobserver agreement. Sleep Breath. 2017, 21, 173-179. [CrossRef]

(C) 2020 by the authors. Licensee MDPI, Basel, Switzerland. This article is an open access article distributed under the terms and conditions of the Creative Commons Attribution (CC BY) license (http://creativecommons.org/licenses/by/4.0/). 